\title{
Identification study of solar cell/module using recent optimization techniques
}

\author{
Mahmoud Abbas El-Dabah ${ }^{1}$, Ragab Abdelaziz El-Sehiemy², Mohamed Ahmed Ebrahim ${ }^{3}$, \\ Zuhair Alaas ${ }^{4}$, Mohamed Mostafa Ramadan ${ }^{4,5}$ \\ ${ }^{1}$ Department of Electrical Engineering, Faculty of Engineering, Al-Azhar University, Cairo, Egypt \\ ${ }^{2}$ Department of Electrical Engineering, Faculty of Engineering, Kafr El-Sheikh University, Kafr El Sheikh, Egypt \\ ${ }^{3}$ Department of Electrical Engineering, Faculty of Engineering at Shoubra, Benha University, Banha, Egypt \\ ${ }^{4}$ Department of Electrical Engineering, Faculty of Engineering, Jazan University, Jazan, Saudi Arabia \\ ${ }^{5}$ Department of Electrical Engineering, Faculty of Engineering, Helwan University, Helwan, Egypt
}

\begin{tabular}{l} 
Article Info \\
\hline Article history: \\
Received Mar 22, 2021 \\
Revised Nov 1, 2021 \\
Accepted Nov 14, 2021 \\
\hline Keywords: \\
Double diode model \\
Optimization algorithms \\
Parameter extraction \\
Runge Kutta optimizer
\end{tabular}

\begin{abstract}
This paper proposes the application of a novel metaphor-free population optimization based on the mathematics of the Runge Kutta method (RUN) for parameter extraction of a double-diode model of the unknown solar cell and photovoltaic (PV) module parameters. The RUN optimizer is employed to determine the seven unknown parameters of the two-diode model. Fitting the experimental data is the main objective of the extracted unknown parameters to develop a generic PV model. Consequently, the root means squared error (RMSE) between the measured and estimated data is considered as the primary objective function. The suggested objective function achieves the closeness degree between the estimated and experimental data. For getting the generic model, applications of the proposed RUN are carried out on two different commercial PV cells. To assess the proposed algorithm, a comprehensive comparison study is employed and compared with several well-matured optimization algorithms reported in the literature. Numerical simulations prove the high precision and fast response of the proposed RUN algorithm for solving multiple PV models. Added to that, the RUN can be considered as a good alternative optimization method for solving power systems optimization problems.
\end{abstract}

This is an open access article under the CC BY-SA license.

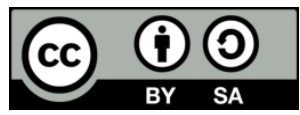

\section{Corresponding Author:}

Mahmoud Abbas El-Dabah

Department of Electrical Engineering, Al-Azhar University

El Mokhayam El Daam Street, Nasr City, Cairo, Egypt

Email: Dr_mdabah@azhar.edu.eg

\section{INTRODUCTION}

The increased demand for electrical energy while decreasing $\mathrm{CO}_{2}$ emission associated with electricity generation requires green renewable energy sources (GRERs). As a source of green energy, photovoltaic (PV) can generate electricity from sunlight using semiconductor materials. Globally, there is a massive increase in solar photovoltaic capacities in comparison with those of wind energy as per the REN21 latest published report in 2021 [1]. The Egyptian government pays a concentration towards the exploitation of available GRERs and PV especially. One of the most significant constructed PV projects in the world was at Benban, Aswan, Egypt, which has an installed capacity of $1.8 \mathrm{GW}$ [2].

Due to this high potential spread, accurate modeling of PVs has a high impact on their performance under varied environmental conditions and shading. To express the non-linearity relationship between current-voltage (I-V) and power-voltage (P-V) of the PV cell, equivalent circuit models will be required. As 
per the literature, the single and double diode equivalent circuit models are used in parameter extraction of PV cells, which can be reviewed in [3]. However, its simplicity and reduced number of estimated parameters of the single diode equivalent circuit model, its precision diminishes at low irradiation levels with temperature variation [4], [5]. The estimated parameters in the single diode model are the photogenerated current, the reverse saturation currents, the series and shunt resistances, and the ideality factor. The double diode equivalent circuit model is composed of seven parameters, five of them the same as five parameters of the single diode in addition to two parameters, which are the reverse saturation current and the ideality factor of the additional diode.

As per the literature review, the parameter extraction techniques of the PV equivalent circuit model can be classified into three categories, namely analytical, numerical (deterministic and stochastic), and hybrid techniques [6], [7]. The analytical methods utilize the power-voltage and current-voltage data curves with the aids of selected data points from the manufacturer datasheets (the open-circuit voltage V_oc, the maximum output power P_m, the short circuit current I_sc, the maximum output current I_m, the maximum output voltage $\mathrm{V} \_\mathrm{m}$ ) to constitute the mathematical parameter estimation problem [8]-[13]. These methods require some mathematical approximations (simplification) to reduce the number of extracted parameters. Although the used approximation provides ease of implementation and less computational effort, however, it has a significant impact on the solution accuracy. In study [14], it was approved that these approaches are less accurate than numerical approaches. To overcome modeling imprecision that may arise if there are inaccurate selected data from datasheets, the measured data of I-V are the same as used in numerical (iterative) techniques. The parameter extraction techniques can be categorized into two categories: deterministic and stochastic (heuristic and meta-heuristic) techniques. The deterministic techniques such as Newton-Raphson [15], linear identification [16], or the Levenberg-Marquardt (LM) algorithm [17] can be used for parameter extraction of PV equivalent circuit parameters. The main drawback of these conventional methods is local optimum trapping due to its sensitivity to the initial solution. As an alternative to the deterministic techniques, the naturally inspired (meta-heuristic) are extensively used in the last decade. In literatures, there are a lot of these methods such as, biogeography-based heterogeneous cuckoo search (BHCS) [18], pattern search (PS) [19], firefly algorithm (FA) [20], ant lion optimizer (ALO) [21], Jaya algorithm [22], salp swarm algorithm (SSA) [23], elephant herd optimizer [24], enhanced sine cosine algorithm (ISCA) [25], hybridized interior search algorithm (HISA) [26], an artificial bee colony-differential evolution (ABC-DE) [27], improved adaptive Nelder-Mead simplex (NMS) hybridized with the artificial bee colony (ABC) metaheuristic, algorithm of hybrid adaptive and Nelder-Mead simplex (EHA-NMS) [28], mutative-scale parallel chaos optimization algorithm (MPCOA) [29], classified perturbation mutation based particle swarm optimization (CPMPSO) [30], heterogeneous comprehensive learning particle swarm optimizer (HCLPSO) [31], and improved shuffled complex evolution (ISCE) [32]. A forensic based optimization algorithm was developed in [33] for finding the optimal parameters of solar cell modules. Another optimizer called turbulent flow of water optimizer in [34] was developed to optimize the parameters of three solar cell models. An assessment study based on the elephant herd optimization, which developed with different versions [35], is compared with closed loop particle swarm optimizer in [36]. The An interval branch and bound global optimization algorithm (IBBGO) that is referred to, interval branch/bound global optimizer, was integrated to find the optimal parameters of three PV models [37].

All these meta-heuristic optimization algorithms aim at minimizing the objective/cost function while balancing between exploration and exploitation phases. At the same time, meta-heuristic optimization algorithms cannot provide robust search capability towards optimal solutions [38]. To overcome these challenges, a novel metaphor-free population optimization based on the mathematics of the Runge Kutta method (RUN) is presented [39]. RUN optimizer balances between exploration and exploitation phases in dynamic behavior. Moreover, the RUN optimization algorithm has a competitive convergence speed as well as an enhanced solution quality to avoid local optimal solutions.

It is cleared that many meta-heuristic optimization algorithms are used for parameter extraction of the equivalent circuit of the PV model. Nevertheless, most of these algorithms have several control parameters that require tuning to achieve better performance for an optimization problem. The RUN algorithm has fewer control parameters due to its specific property which depends on the main logic of the Runge Kutta technique. This advantage motivates the authors of the presented article to use it in parameter estimation of the double diode model of PV cell/module. The main contribution of this research can be summarized as: i) develop RUN optimization algorithm for PV parameter extraction based on double diode model, ii) assessment of the extracted parameter using RUN with the recent optimization algorithms, iii) recommending the best method and best equivalent circuit model to be used for PV cell/module, and iv) the proposed RUN has the best convergence rates compared with the competitive methods.

This paper will be organized as follows: After this section, problem formulation will be introduced in section 2. Section 3 will develop the RUN optimization algorithm for use in parameter extraction of a PV 
cell/module. Application of the proposed algorithm to different commercial cell/module and test results will be emphasized in section 4 . Section 5 will conclude the results drawn from this research.

\section{PROBLEM FORMULATION}

\subsection{Electrical models}

Mathematical modeling of PV cell/module equivalent circuits will be illustrated. The equivalent circuit models emulate the non-linear (I-V) and (P-V) relationships of the PV cell. This model is considered as the simplest equivalent circuit model. It has five parameters which are the photogenerated current $I_{p h}$, series and shunt resistances $R_{S}, R_{s h}$, the ideality factor $n$ and the reverse saturation current $I_{R S}$ as shown in Figure 1(a). The load current I of solar cells can be represented by (1):

$$
I=I_{p h}-I_{R S-1}\left[\exp \left(\frac{V+I R_{s}}{n V_{t}}-1\right)\right]-\frac{\left(V+I R_{s}\right)}{R_{s h}}
$$

In this model, the recombination of generated charge carriers was neglected. Moreover, its precision diminishes at low irradiation levels with temperature variation [4]-[6]. The recombination effect was modeled in the double diode model that is presented in Figure 1(b), the load current $I$ of solar cells can be represented by (2):

$$
I=I_{p h}-I_{R S-1}\left[\exp \left(\frac{V+I R_{s}}{n_{1} V_{t}}-1\right)\right]-I_{R S-2}\left[\exp \left(\frac{V+I R_{s}}{n_{2} V_{t}}-1\right)\right]-\frac{\left(V+I R_{s}\right)}{R_{s h}}
$$

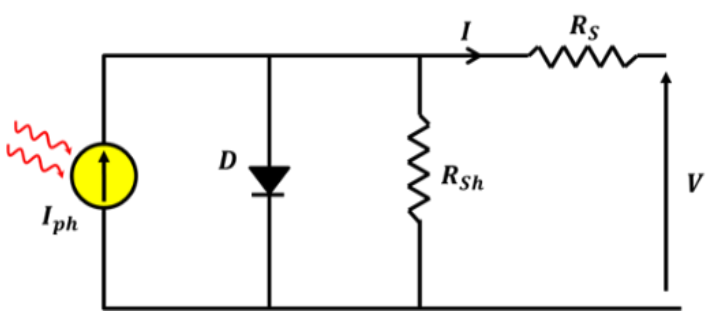

(a)

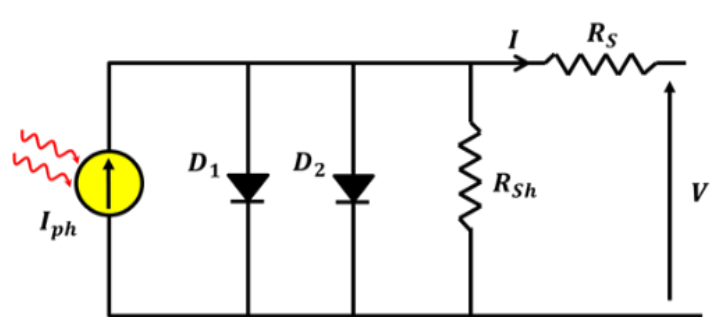

(b)

Figure 1. Diode equivalent circuit models, (a) single and (b) double

\subsection{Mathematical representation of parameter extraction problem}

The parameter extraction problem is considered an optimization problem. The main objective of the estimation problem is to minimize the variance between the experimental data and simulated results so that the optimal values of these unknown model parameters can be extracted. The objective function is defined as the overall root mean square error (RMSE). For N-measurements, the objective function is formulated as [38] as in (3):

$$
\operatorname{RMSE}(x)=\sqrt{\frac{1}{N} \sum_{k=1}^{N}\left[f\left(V_{k}, I_{k}, x\right)-I_{k}\right]^{2}}
$$

where, $x=\left\{I_{p h}, I_{R S-1}, I_{R S-2}, R_{S}, R_{S h}, n_{1}, n_{2}\right\}$ and the $f\left(V_{k}, I_{k}, x\right)$ is used for current calculation from (2).

\section{RUNGE KUTTA OPTIMIZER (RUN)}

The Runge Kutta-based optimization (RUN) is a novel optimization algorithm proposed in [39]. The RUN is developed based on the mathematics of the Runge Kutta method. It is inspired by the logic of slope variations computed by the Runge Kutta method as a promising and logical searching mechanism for global optimization. In RUN, three distinctive phases are simulated. These phases are active exploration and exploitation phases for exploring the promising regions in the feature space and constructive toward the global best solution. Moreover, in the last phase, an enhanced solution quality mechanism is employed to 
avoid the local optimal solutions and increase convergence speed. Figure 2 demonstrates the phases of the proposed RUN algorithm. The phases of the suggested RUN optimizer are discussed in detail in the following sub-sections.

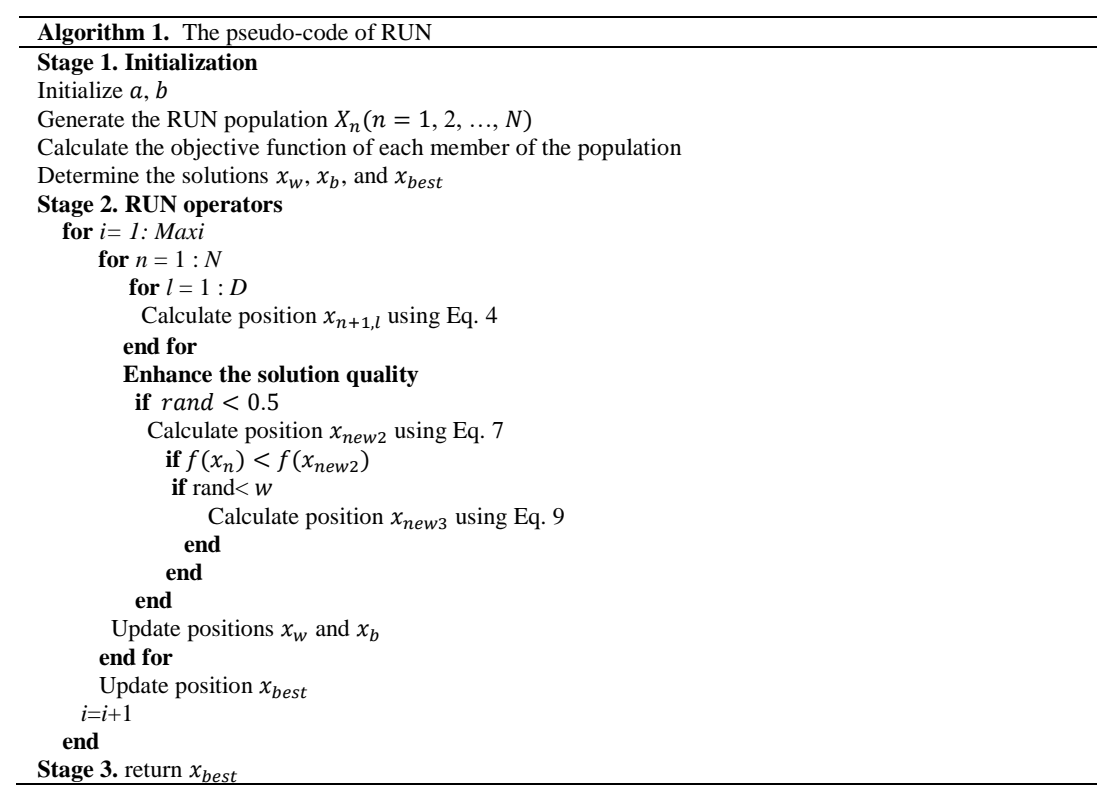

Figure 2. Pseudo-code of the proposed algorithm (RUN)

\subsection{Updating solutions stage}

In the updating solutions stage, the RUN uses a search mechanism (SM) based on the runge kutta method to update the position of the current solution at each iteration, which is defined as (4):

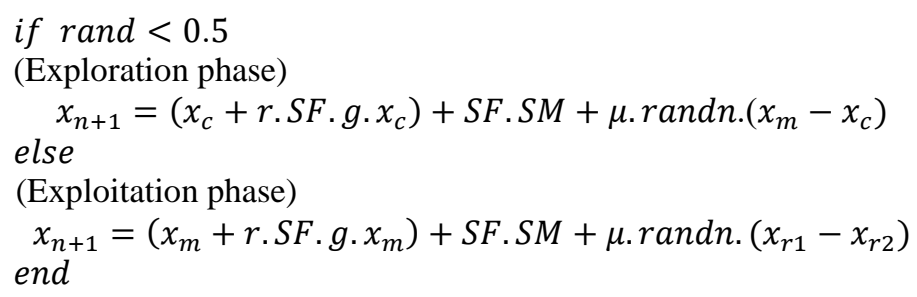

where, $r$ is an integer number, which is 1 or-1. $g$ is a random number in the range [0,2]. $S F$ is an adaptive factor. Where, $\mu$ is a random number. The formula of $S M$ is defined in [34]. The formula of $S F$ is as (5):

$$
S F=2 .(0.5-\text { rand }) \times f
$$

where, $f=a \times \exp \left(-b \times \operatorname{rand} \times\left(\frac{i}{\text { Maxi }}\right)\right)$, Maxi stands for the largest number of iterations. The formula of $x_{c}$ and $x_{m}$ are as (6):

$$
\begin{aligned}
& x_{c}=\varphi \times x_{n}+(1-\varphi) \times x_{r 1} \\
& x_{m}=\varphi \times x_{\text {best }}+(1-\varphi) \times x_{\text {lbest }}
\end{aligned}
$$

where, $\varphi$ is a random number in the range of $(0,1) . x_{\text {best }}$ is the best-so-far solution. $x_{\text {lbest }}$ is the best position obtained at each iteration.

\subsection{Enhanced solution quality stage}

In the RUN algorithm, enhanced solution quality (ESQ) is employed to increase the quality of solutions and to avoid local optima in each iteration. The following scheme is executed to create the solution $\left(x_{\text {new } 2}\right)$ by using the ESQ (7), (8): 


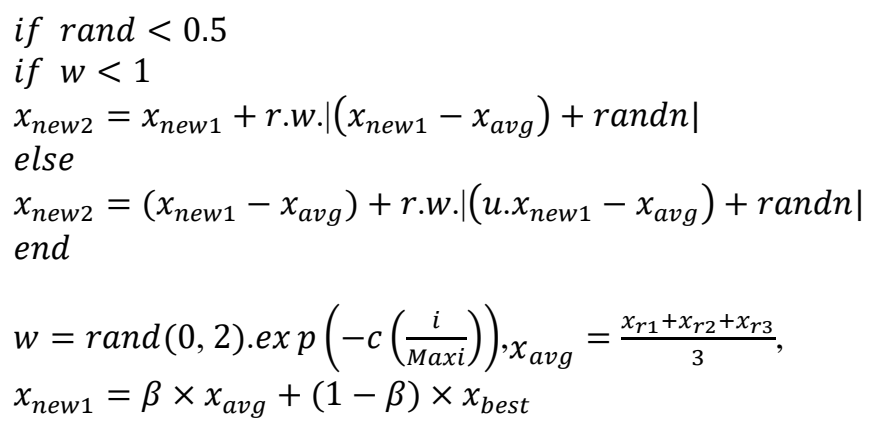

where, $\beta$ is a random number in the range of $[0,1] . c$ is a random number, which is equal to $5 \times$ rand in this study. $r$ is an integer number, which is 1,0 , or-1. $x_{\text {best }}$ is the best solution explored so far. The solution calculated in this part $\left(x_{\text {new } 2}\right)$ may not have better fitness than that of the current solution (i.e., $f\left(x_{\text {new } 2}\right)>$ $f\left(x_{n}\right)$ ). To have another chance for creating a good solution, another new solution $\left(x_{n e w 3}\right)$ is generated, which is defined as in (9),

$$
\begin{aligned}
& \text { if rand }<w \\
& x_{n e w 3}=\left(x_{n e w 2}-\text { rand. } x_{n e w 2}\right)+S F .\left(\text { rand. } x_{R K}+\left(v . x_{b}-x_{n e w 2}\right)\right) \\
& \text { end }
\end{aligned}
$$

where $v$ is a random number with a value of $2 \times$ rand.

\section{SIMULATION AND RESULT}

To assess the proposed algorithm, a comprehensive study is employed compared with several previous optimization algorithms. Numerical simulations on different commercial PV cells/modules will be illustrated below. To evaluate the performance of the proposed algorithm, A set of standard data for a commercial silicon solar cell (made by R.T.C. company from France) with a diameter of $57 \mathrm{~mm}$, at a temperature of $33{ }^{\circ} \mathrm{C}$, and 1 sun $\left(1,000 \mathrm{~W} / \mathrm{m}^{2}\right)$ [40]. The PhotowattPWP201 PV commercial module with 36 polycrystalline silicon cells connected in series, operating under an irradiance of $1,000 \mathrm{~W} / \mathrm{m}^{2}$ and temperature of $45{ }^{\circ} \mathrm{C}$ [41]. Table 1 summarizes the datasheets of the selected commercial PV cell/module to be tested in this work. The boundary constraints of the extracted parameters are given in Table 2. The proposed RUNbased model and the other comparative algorithms are executed by the authors via the matrix laboratory (MATLAB) 2017a platform using an Intel ${ }^{\circledR}$ core TM i5-7200U CPU, $2.50 \mathrm{GHz}, 8 \mathrm{~GB}$ RAM Laptop. Accuracy examination of the proposed optimization RUN algorithm for parameters identification will be additionally accomplished by the current calculation based on the values estimated for the two models considered for comparison with that taken from the experimental measurements. The error concerning each of the measured values was evaluated by relative error (RE) and individual absolute error (IAE), calculated as given in (10) and (11), respectively.

$$
\begin{aligned}
& R E=\left(I_{\text {Measured }}-I_{\text {Estimated }}\right) / I_{\text {Measured }} \\
& I A E=\left|I_{\text {Measured }}-I_{\text {Estimated }}\right|
\end{aligned}
$$

Table 1. Datasheets of selected cell/module for study

\begin{tabular}{ccccccccc}
\hline Company & Cell type & $\mathrm{V}_{\mathrm{oc}}[\mathrm{V}]$ & $\mathrm{I}_{\mathrm{sc}}[\mathrm{A}]$ & $\mathrm{V}_{\mathrm{m}}[\mathrm{V}]$ & $\mathrm{I}_{\mathrm{m}}[\mathrm{A}]$ & $\mathrm{P}_{\mathrm{m}}[\mathrm{W}]$ & Reference temp. $\left[{ }^{\circ} \mathrm{C}\right]$ & \# of cells / module \\
\hline France solar & NA & 0.5728 & 0.76 & 0.45 & 0.691 & 11.315 & 33 & 1 \\
Photowatt & Polycrystalline & 16.778 & 1.03 & 12.60 & 0.898 & 0.311 & 45 & 36 \\
\hline
\end{tabular}

Table 2. Boundary constraints of the extracted parameters

\begin{tabular}{ccccccc}
\hline Model & \multicolumn{5}{c}{ Parameters } \\
\hline France solar & & $I_{p h}[\mathrm{~A}]$ & $I_{R S 1,2}[\mu A]$ & $R_{S}[\Omega]$ & $R_{S h}[\Omega]$ & $n_{1,2}$ \\
& Min & 0 & 0 & 0 & 0 & 1 \\
Photowatt 201 & Max & 1 & 1 & 0.5 & 100 & 2 \\
& Min & 0 & 0 & 0 & 0 & 1 \\
& Max & 2 & 10 & 0.5 & 3000 & 2 \\
\hline
\end{tabular}




\subsection{RTC. france solar cell}

For RTC solar cell model, the optimal parameters attained using different optimization techniques are presented in Table 3. The solar cell parameters estimated using the RUN algorithm have the lowest RMSE value. Figure 3 demonstrates that the estimated I-V and P-V characteristics using RUN are identical compared to the measurement as well as the datasheet. Table 4 spots the light on the coincidence between both the measured and estimated values for voltage and current. The results of MPP are highlighted in green in Table 4 and illustrated in Figure 3. As can be concluded from Figure 4, RUN has the lowest RMSE value (0.0009829) in comparison with sunflower optimization (SFO), which has the highest value (0.002). On the other hand, RUN has the lowest execution time of $(9.95 \mathrm{~s})$ in comparison with SFO, which has the highest execution time of (44.402 s).

Table 3. Optimum parameter settings using different optimization techniques for RTC France solar cell

\begin{tabular}{cccccccc}
\hline & RCGA & CSA & SSA & PSO & SFO & GW-CS & RUN \\
\hline $\boldsymbol{I}_{\boldsymbol{p h}}(\boldsymbol{A})$ & 0.7606 & 0.7608 & 0.7604 & 0.76077 & 0.76275 & 0.76002 & 0.76077 \\
$\boldsymbol{I}_{\boldsymbol{R S}-\mathbf{1}}(\boldsymbol{\mu} \boldsymbol{A})$ & 0.3743 & 0.6489 & 0.3165 & 0.6680 & 0.2452 & 0.2272 & 0.22266 \\
$\boldsymbol{I}_{\boldsymbol{R} \boldsymbol{S}-\boldsymbol{2}}(\boldsymbol{\mu} \boldsymbol{A})$ & 0.0731 & 0.2199 & 0.1728 & 0.2389 & 0.8324 & 0.2553 & 0.67737 \\
$\boldsymbol{R}_{\boldsymbol{S}}(\boldsymbol{\Omega})$ & 0.0357 & 0.0367 & 0.0369 & 0.0366 & 0.0339 & 0.0359 & 0.03674 \\
$\boldsymbol{R}_{\boldsymbol{s} \boldsymbol{h}}(\boldsymbol{\Omega})$ & 60.823 & 54.946 & 59.7711 & 55.691 & 51.165 & 67.0574 & 55.4973 \\
$\boldsymbol{n}_{\mathbf{1}}$ & 1.4968 & 1.9454 & 1.69629 & 2.000 & 1.4768 & 1.4632 & 1.45006 \\
$\boldsymbol{n}_{\boldsymbol{2}}$ & 1.9607 & 1.4493 & 1.43602 & 1.4559 & 1.7895 & 1.6630 & 1.96604 \\
RMSE & 0.0010 & 0.000985 & 0.00103 & 0.00098 & 0.002 & 0.00110 & 0.0009829 \\
Duration $[\mathrm{s}]$ & 13.655 & 11.524 & 10.1512 & 10.567 & 44.402 & 14.131 & 9.95 \\
\hline
\end{tabular}

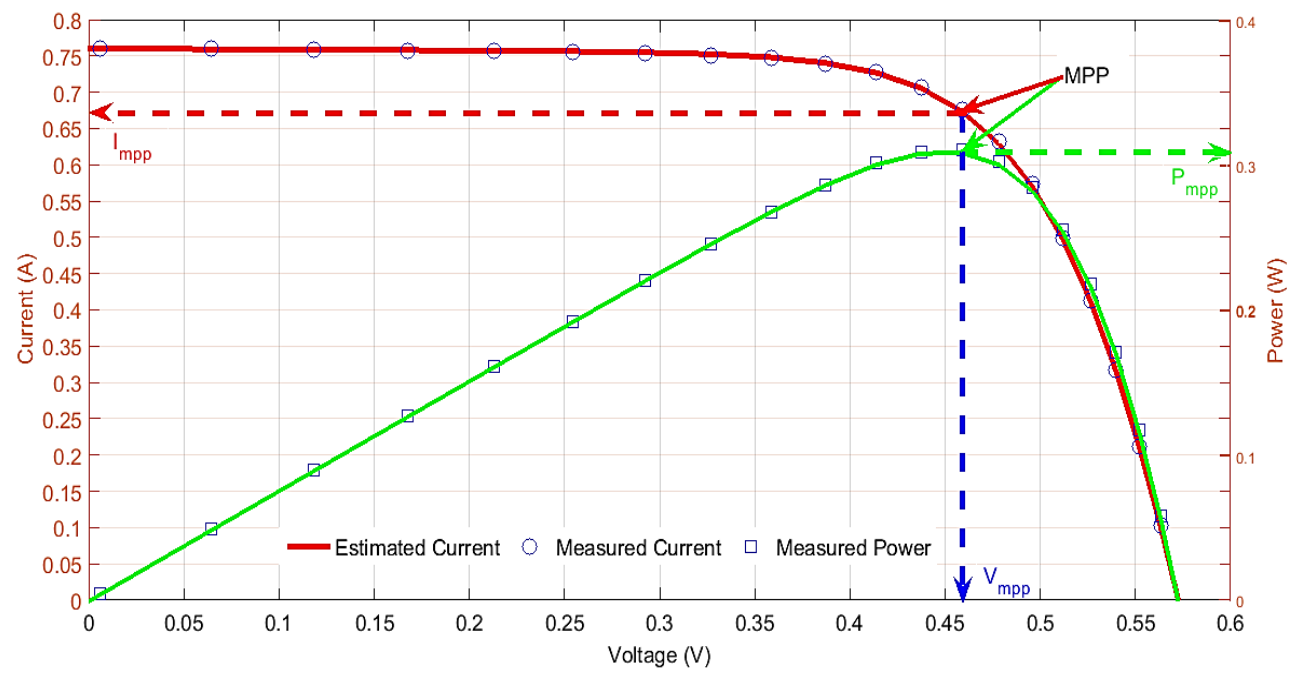

Figure 3. The coincidence between measured and estimated results in V-I and V-P curves of RTC-solar cell

Table 4. The relative error for each measurement using a RUN-based two diode model

\begin{tabular}{|c|c|c|c|c|c|c|c|c|c|}
\hline $\begin{array}{c}\text { Measured } \\
\text { Voltage }\end{array}$ & $\begin{array}{c}\text { Measured } \\
\text { current }\end{array}$ & $\begin{array}{c}\text { Estimated } \\
\text { current }\end{array}$ & IAE & $\mathrm{RE}$ & $\begin{array}{c}\text { Measured } \\
\text { Voltage }\end{array}$ & $\begin{array}{c}\text { Measured } \\
\text { current }\end{array}$ & $\begin{array}{l}\text { Estimate } \\
\text { d current }\end{array}$ & IAE & $\mathrm{RE}$ \\
\hline-0.2057 & 0.764 & 0.7640 & 0.0000 & 0.0000 & 0.4373 & 0.728 & 0.7399 & 0.0014 & 0.0019 \\
\hline-0.1291 & 0.762 & 0.7626 & 0.0006 & 0.0008 & 0.4590 & 0.7065 & 0.7271 & 0.0009 & 0.0012 \\
\hline 0.0057 & 0.7605 & 0.7602 & 0.0003 & 0.0004 & 0.4784 & 0.632 & 0.6748 & 0.0007 & 0.0010 \\
\hline 0.0646 & 0.7600 & 0.7591 & 0.0009 & 0.0012 & 0.4960 & 0.573 & 0.6302 & 0.0018 & 0.0029 \\
\hline 0.2132 & 0.7570 & 0.7562 & 0.0008 & 0.0010 & 0.5398 & 0.3165 & 0.4118 & 0.0012 & 0.0030 \\
\hline 0.2545 & 0.7555 & 0.7552 & 0.0003 & 0.0004 & 0.5521 & 0.212 & 0.3150 & 0.0015 & 0.0046 \\
\hline 0.2924 & 0.7540 & 0.7537 & 0.0003 & 0.0004 & 0.5633 & 0.1035 & 0.2095 & 0.0025 & 0.0119 \\
\hline 0.3269 & 0.7505 & 0.7514 & 0.0009 & 0.0012 & 0.5736 & -0.01 & 0.0997 & 0.0038 & 0.0368 \\
\hline 0.3585 & 0.7465 & 0.7473 & 0.0008 & 0.0010 & 0.5833 & -0.123 & -0.0126 & 0.0026 & -0.2618 \\
\hline
\end{tabular}




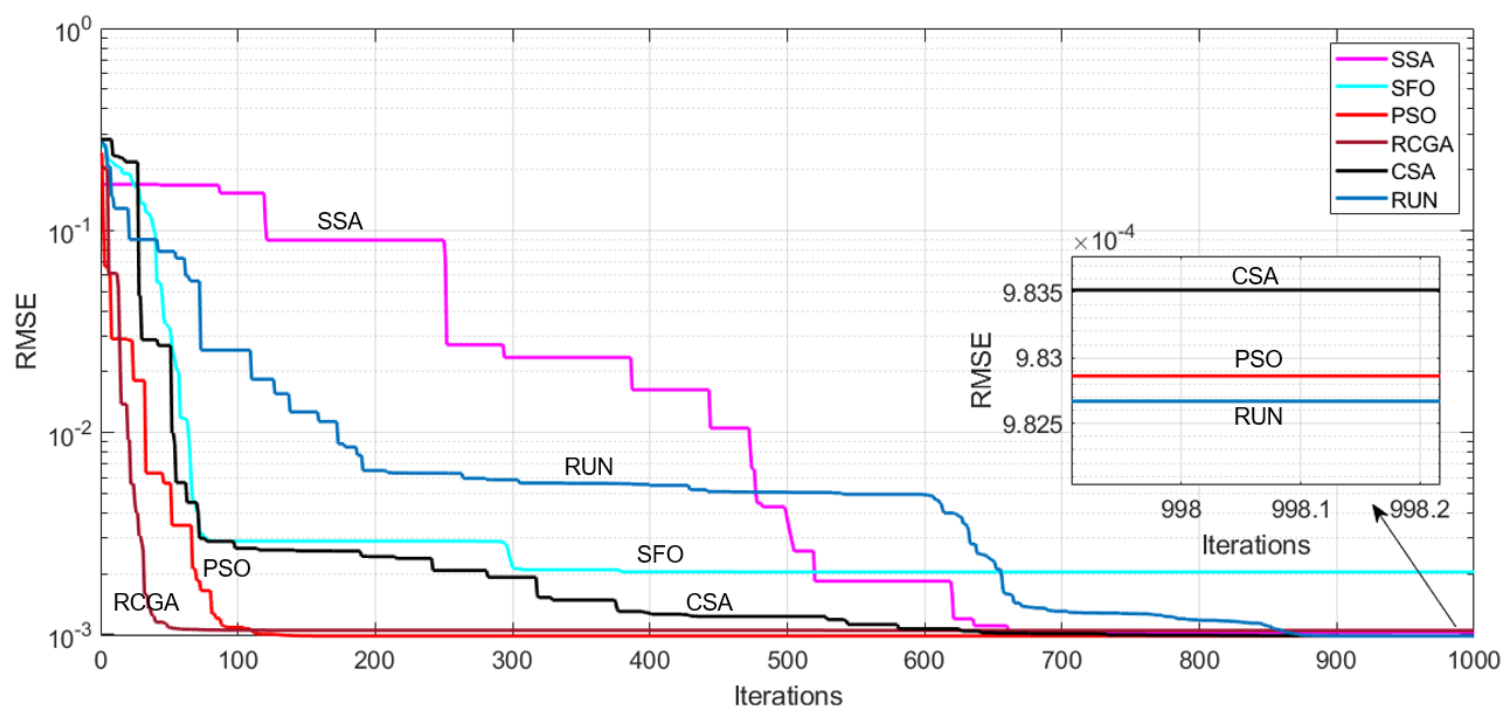

Figure 4. The objective function of the competitive estimation algorithms

\subsection{Photo watt PWP201}

In the Photowatt PWP201 module, from the obtained results in Tables 5 and 6, the RUN has the lowest RMSE value (0.003139) among the competitive optimization algorithms. The maximum power point (MPP) is highlighted in green in Table 6 and illustrated clearly in Figure 5. The RMSE for all optimization techniques are plotted in Figure 6. Generally speaking, RUN has the lowest RMSE value (0.003139) compared to all the applied optimization techniques. The crow search algorithm (CSA) comes in the first class in terms of execution time with (10.2910 s) in comparison with the SFO with (46.7350 s), which has the highest value of elapsed time.

Table 5. Optimum parameter settings using competitive optimization algorithms for Photowatt-PWP201

\begin{tabular}{cccccccc}
\hline & RCGA & CSA & SSA & PSO & SFO & GW-CS & RUN \\
\hline $\boldsymbol{I}_{\boldsymbol{p} \boldsymbol{h}}(\boldsymbol{A})$ & 1.0252 & 1.0258 & 1.02867 & 1.0258 & 1.01883 & 1.02574 & 1.0270 \\
$\boldsymbol{I}_{\boldsymbol{R} \boldsymbol{S}-\mathbf{1}}(\boldsymbol{\mu} \boldsymbol{A})$ & 5.1463 & 9.8979 & 7.59250 & 3.8226 & 0.2769 & 0.2527 & 1.4074 \\
$\boldsymbol{I}_{\boldsymbol{R} \boldsymbol{S}-\mathbf{2}}(\boldsymbol{\mu} \boldsymbol{A})$ & 2.4599 & 3.8944 & 7.53697 & 5.0705 & 0.9499 & 6.01257 & 5.5321 \\
$\boldsymbol{R}_{\boldsymbol{S}}(\boldsymbol{\Omega})$ & 0.0321 & 0.0322 & 0.02864 & 0.03175 & 0.03724 & 0.03191 & 0.0321 \\
$\boldsymbol{R}_{\boldsymbol{s h}}(\boldsymbol{\Omega})$ & 1000 & 1001 & 629.437 & 1000 & 351.092 & 248.962 & 100.3905 \\
$\boldsymbol{n}_{\mathbf{1}}$ & 1.3982 & 1.877 & 1.48011 & 1.7271 & 1.32756 & 1.89869 & 1.9920 \\
$\boldsymbol{n}_{\mathbf{2}}$ & 1.767 & 1.3723 & 1.61563 & 1.4007 & 1.23380 & 1.41230 & 1.4034 \\
RMSE & 0.0035 & 0.0035 & 0.00491 & 0.00349 & 0.00734 & 0.00347 & 0.003139 \\
Duration[s] & 12.0730 & 10.2910 & 19.5530 & 10.4660 & 46.7350 & 11.4380 & 11.25 \\
\hline
\end{tabular}

Note: RCGA= real coded genatic algorithm, SSA = introduced in the introduction, PSO is particle swarm optimization,

GW-CS = gray wolf cuckoo search algorithm

Table 6. The relative error for each measurement using a RUN-based two diode model

\begin{tabular}{cccccccccc}
\hline $\begin{array}{c}\text { Measured } \\
\text { voltage }\end{array}$ & $\begin{array}{c}\text { Measured } \\
\text { current }\end{array}$ & $\begin{array}{c}\text { Estimated } \\
\text { current }\end{array}$ & IAE & RE & $\begin{array}{c}\text { Measured } \\
\text { Voltage }\end{array}$ & $\begin{array}{c}\text { Measured } \\
\text { current }\end{array}$ & $\begin{array}{c}\text { Estimated } \\
\text { current }\end{array}$ & IAE & RE \\
\hline 1.9426 & 1.0345 & 1.0272 & 0.0073 & 0.0070 & 12.6490 & 0.9120 & 0.9227 & 0.0028 & 0.0030 \\
0.1248 & 1.0315 & 1.0266 & 0.0049 & 0.0047 & 13.1231 & 0.8725 & 0.9117 & 0.0003 & 0.0003 \\
1.8093 & 1.0300 & 1.0261 & 0.0039 & 0.0038 & 14.2221 & 0.7265 & 0.8715 & 0.0010 & 0.0012 \\
3.3511 & 1.0260 & 1.0256 & 0.0004 & 0.0004 & 14.6995 & 0.6345 & 0.7264 & 0.0001 & 0.0002 \\
4.7622 & 1.0220 & 1.0249 & 0.0029 & 0.0029 & 15.1346 & 0.5345 & 0.6352 & 0.0007 & 0.0010 \\
6.0538 & 1.0180 & 1.0239 & 0.0059 & 0.0058 & 15.5311 & 0.4275 & 0.5349 & 0.0004 & 0.0007 \\
7.2364 & 1.0155 & 1.0222 & 0.0067 & 0.0066 & 15.8929 & 0.3185 & 0.4285 & 0.0010 & 0.0024 \\
8.3189 & 1.0140 & 1.0189 & 0.0049 & 0.0049 & 16.2229 & 0.2085 & 0.3188 & 0.0003 & 0.0010 \\
9.3097 & 1.0100 & 1.0131 & 0.0031 & 0.0031 & 16.5241 & 0.1010 & 0.2083 & 0.0002 & 0.0009 \\
10.2163 & 1.0035 & 1.0029 & 0.0006 & 0.0006 & 16.7987 & -0.0080 & 0.0989 & 0.0021 & 0.0204 \\
11.0449 & 0.9880 & 0.9862 & 0.0018 & 0.0018 & 17.0499 & -0.1110 & -0.0076 & 0.0004 & -0.0472 \\
11.8018 & 0.9630 & 0.9603 & 0.0027 & 0.0028 & 17.2793 & -0.2090 & -0.1106 & 0.0004 & -0.0034 \\
12.4929 & 0.9255 & 1.0272 & 0.0073 & 0.0070 & 17.4885 & -0.3030 & -0.2091 & 0.0001 & -0.0005 \\
\hline
\end{tabular}




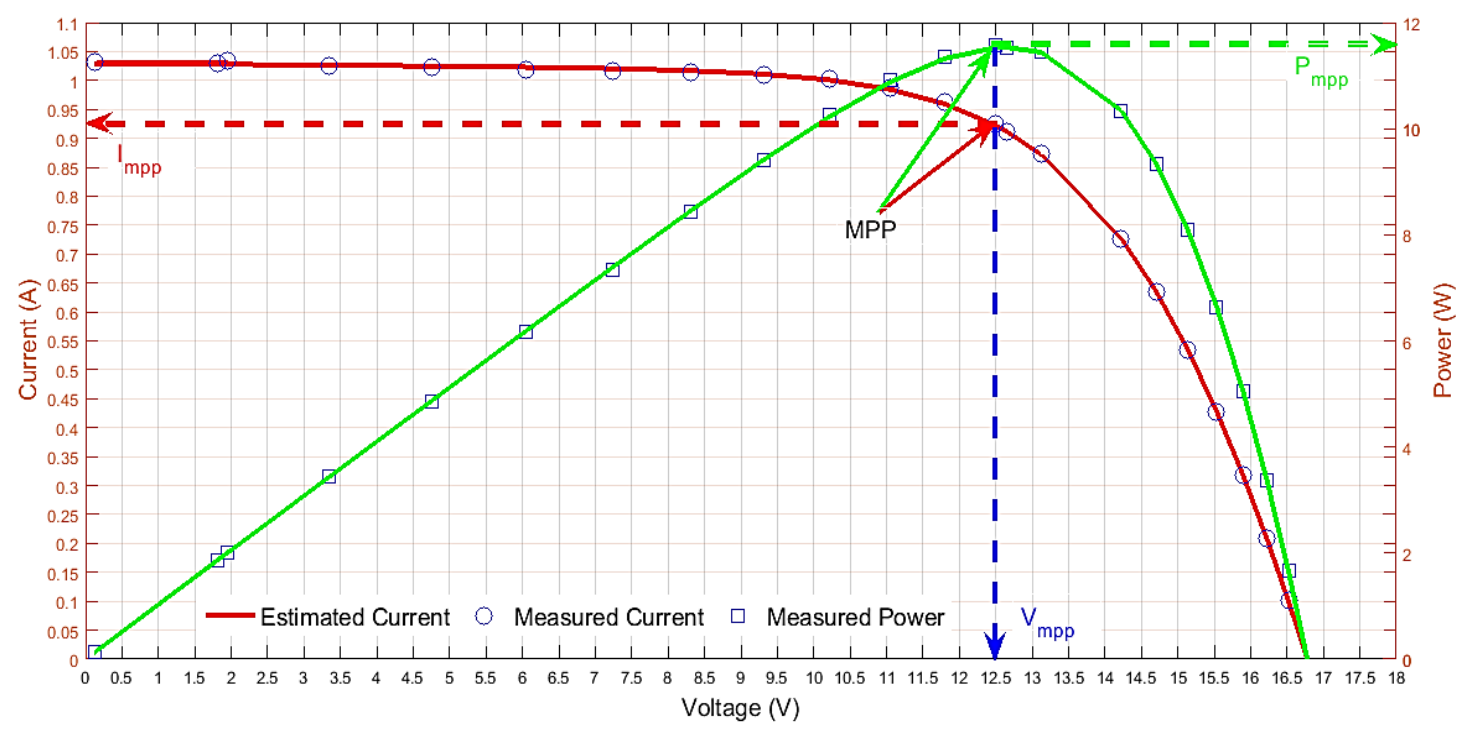

Figure 5. The coincidence between measured and estimated results in V-I and V-P curves of PWP201

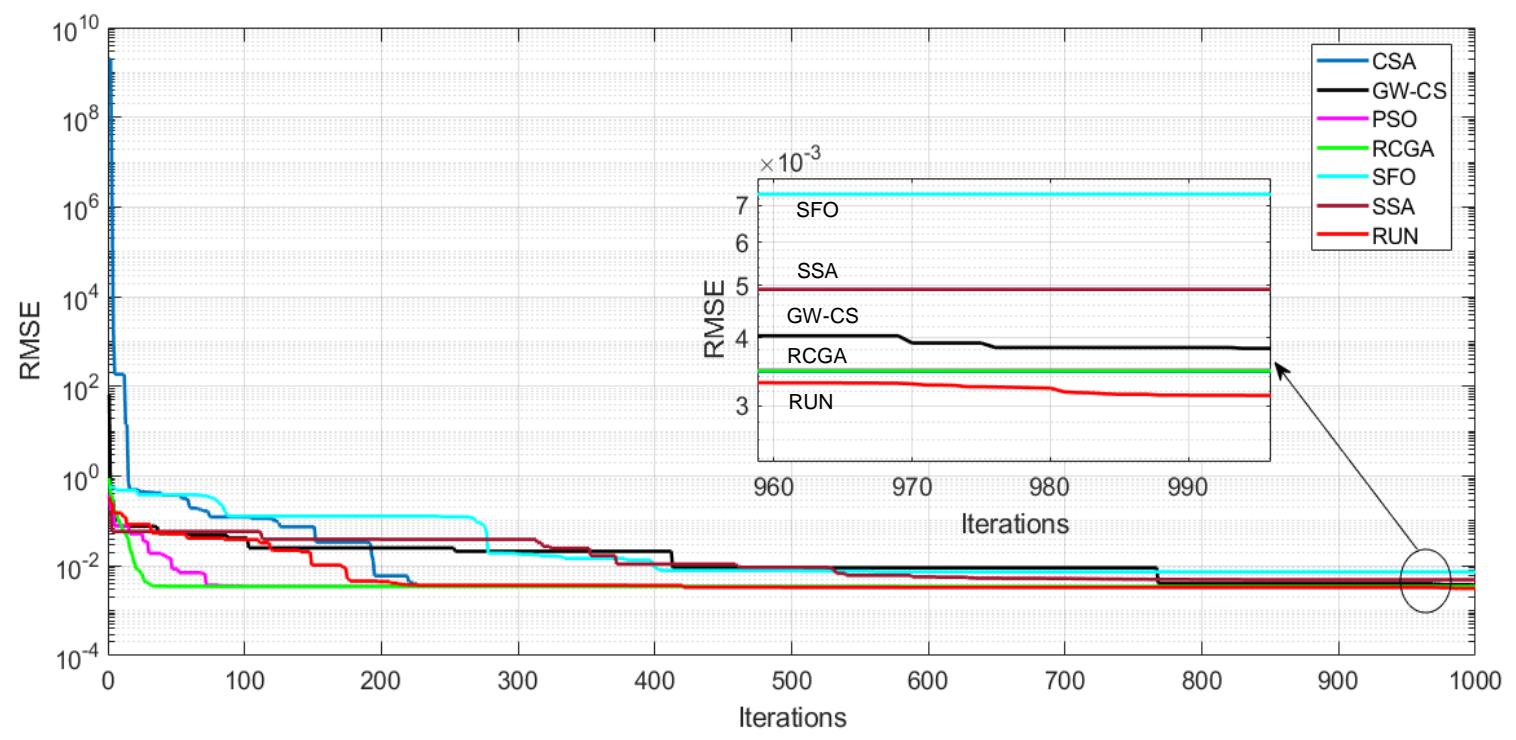

Figure 6. The convergence rates of objective function decline using competitive algorithms

\section{CONCLUSION}

This manuscript presents a new physical implementation of modern inspired optimization algorithms called RUN for PV cells/modules parameter estimation. To validate and verify the main findings, the proposed algorithm was implemented and tested on two commercial cells/modules. Moreover, a comprehension comparison of the latest meta-heuristic optimization algorithms was illustrated. The attained theoretical and experimental results are coincident, which proves the superiority of RUN in the field of parameter estimation for PV cells/modules. The results signify the effectiveness and reliability of the proposed RUN in estimating the accurate double diode model of two practical PV cells/modules. The RUN realizes steady convergence rates than other competitive algorithms. Finally, the main findings of this article will pave the way for the authors as well as the researchers to evaluate the impact of the estimated parameters in emulating PV equivalent circuits under various real operating conditions.

\section{REFERENCES}

[1] IRENA, Renewable capacity statistics. International Renewable Energy Agency (IRENA), 2021. 
[2] NREA, "Strategic environmental and social assessment of wind energy projects in the East Nile Region (Arab Republic of Egypt)," in "Non of the technical summary final draft (NTS) SESA wind report," New and Renewable Energy Authority (NREA) Ministry of Electricity and Renewable Energy, Egypt, 2018.

[3] A. R. Jordehi, "Parameter estimation of solar photovoltaic (PV) cells: A review," Renewable and Sustainable Energy Reviews, vol. 61, pp. 354-371, Aug. 2016, doi: 10.1016/j.rser.2016.03.049.

[4] Z. Salam, K. Ishaque, and H. Taheri, "An improved two-diode photovoltaic (PV) model for PV system," in 2010 Joint International Conference on Power Electronics, Drives and Energy Systems \& 2010 Power India, Dec. 2010, pp. 1-5, doi: 10.1109/PEDES.2010.5712374.

[5] K. Ishaque, Z. Salam, and H. Taheri, “Accurate MATLAB simulink PV system simulator based on a two-diode model," Journal of Power Electronics, vol. 11, no. 2, pp. 179-187, Mar. 2011, doi: 10.6113/JPE.2011.11.2.179.

[6] M. Ćalasan, S. H. E. A. Aleem, and A. F. Zobaa, "On the root mean square error (RMSE) calculation for parameter estimation of photovoltaic models: A novel exact analytical solution based on Lambert W function," Energy Conversion and Management, vol. 210, Apr. 2020, Art. no. 112716, doi: 10.1016/j.enconman.2020.112716.

[7] F. Ayala-Mató, D. Seuret-Jiménez, J. J. Escobedo-Alatorre, O. Vigil-Galán, and M. Courel, "A hybrid method for solar cell parameter estimation," Journal of Renewable and Sustainable Energy, vol. 9, no. 6, Nov. 2017, Art. no. 063504, doi: 10.1063/1.4985953.

[8] Y. Chaibi, M. Salhi, A. El-jouni, and A. Essadki, "A new method to extract the equivalent circuit parameters of a photovoltaic panel," Solar Energy, vol. 163, pp. 376-386, Mar. 2018, doi: 10.1016/j.solener.2018.02.017.

[9] A. Şentürk, "New method for computing single diode model parameters of photovoltaic modules," Renewable Energy, vol. 128, pp. 30-36, Dec. 2018, doi: 10.1016/j.renene.2018.05.065

[10] A. Ayang et al., "Maximum likelihood parameters estimation of single-diode model of photovoltaic generator," Renewable Energy, vol. 130, pp. 111-121, Jan. 2019, doi: 10.1016/j.renene.2018.06.039.

[11] F. J. Toledo, J. M. Blanes, and V. Galiano, "Two-step linear least-squares method for photovoltaic single-diode model parameters extraction," IEEE Transactions on Industrial Electronics, vol. 65, no. 8, pp. 6301-6308, Aug. 2018, doi: 10.1109/TIE.2018.2793216.

[12] H. El Achouby, M. Zaimi, A. Ibral, and E. M. Assaid, "New analytical approach for modelling effects of temperature and irradiance on physical parameters of photovoltaic solar module," Energy Conversion and Management, vol. 177, pp. 258-271, Dec. 2018, doi: 10.1016/j.enconman.2018.09.054.

[13] E. Cuce, P. M. Cuce, I. H. Karakas, and T. Bali, "An accurate model for photovoltaic (PV) modules to determine electrical characteristics and thermodynamic performance parameters," Energy Conversion and Management, vol. 146, pp. 205-216, Aug. 2017, doi: 10.1016/j.enconman.2017.05.022.

[14] D. Allam, D. A. Yousri, and M. B. Eteiba, "Parameters extraction of the three diode model for the multi-crystalline solar cell/module using Moth-Flame Optimization Algorithm," Energy Conversion and Management, vol. 123, pp. 535-548, Sep. 2016, doi: 10.1016/j.enconman.2016.06.052.

[15] M. Louzazni, A. Khouya, K. Amechnoue, M. Mussetta, and A. Crăciunescu, "Comparison and evaluation of statistical criteria in the solar cell and photovoltaic module parameters' extraction," International Journal of Ambient Energy, vol. 41, no. 13, pp. 1482-1494, Nov. 2020, doi: 10.1080/01430750.2018.1517678.

[16] H. M. Ridha, C. Gomes, and H. Hizam, "Estimation of photovoltaic module model's parameters using an improved electromagnetic-like algorithm," Neural Computing and Applications, vol. 32, no. 16, pp. 12627-12642, Aug. 2020, doi: 10.1007/s00521-020-04714-z.

[17] F. Dkhichi, B. Oukarfi, A. Fakkar, and N. Belbounaguia, "Parameter identification of solar cell model using LevenbergMarquardt algorithm combined with simulated annealing," Solar Energy, vol. 110, pp. 781-788, Dec. 2014, doi: 10.1016/j.solener.2014.09.033.

[18] X. Chen and K. Yu, "Hybridizing cuckoo search algorithm with biogeography-based optimization for estimating photovoltaic model parameters," Solar Energy, vol. 180, pp. 192-206, Mar. 2019, doi: 10.1016/j.solener.2019.01.025.

[19] A. M. Beigi and A. Maroosi, "Parameter identification for solar cells and module using a hybrid firefly and pattern search algorithms," Solar Energy, vol. 171, pp. 435-446, Sep. 2018, doi: 10.1016/j.solener.2018.06.092.

[20] R. A. P. Franco, G. L. Filho, and F. H. T. Vieira, "Firefly algorithm applied to the estimation of the parameters of a photovoltaic panel model," Springer International Publishing, 2019, pp. 101-134.

[21] K. G. and Harish Kumar, "Modeling of solar cell under different conditions by Ant Lion optimizer with LambertW function," Applied Soft Computing, vol. 71, pp. 141-151, Oct. 2018, doi: 10.1016/j.asoc.2018.06.025.

[22] K. Yu, B. Qu, C. Yue, S. Ge, X. Chen, and J. Liang, "A performance-guided JAYA algorithm for parameters identification of photovoltaic cell and module," Applied Energy, vol. 237, pp. 241-257, Mar. 2019, doi: 10.1016/j.apenergy.2019.01.008.

[23] R. Abbassi, A. Abbassi, A. A. Heidari, and S. Mirjalili, "An efficient salp swarm-inspired algorithm for parameters identification of photovoltaic cell models," Energy Conversion and Management, vol. 179, pp. 362-372, Jan. 2019, doi: 10.1016/j.enconman.2018.10.069.

[24] A. A. Zaky et al., "Optimal performance emulation of PSCs using the elephant herd algorithm associated with experimental validation," ECS Journal of Solid State Science and Technology, vol. 8, no. 12, pp. Q249-Q255, Dec. 2019, doi: $10.1149 / 2.0271912$ jss.

[25] H. Chen, S. Jiao, A. A. Heidari, M. Wang, X. Chen, and X. Zhao, "An opposition-based sine cosine approach with local search for parameter estimation of photovoltaic models," Energy Conversion and Management, vol. 195, pp. 927-942, Sep. 2019, doi: 10.1016/j.enconman.2019.05.057.

[26] D. Kler, Y. Goswami, K. P. S. Rana, and V. Kumar, "A novel approach to parameter estimation of photovoltaic systems using hybridized optimizer," Energy Conversion and Management, vol. 187, pp. 486-511, May 2019, doi: 10.1016/j.enconman.2019.01.102.

[27] O. Hachana, K. E. Hemsas, G. M. Tina, and C. Ventura, "Comparison of different metaheuristic algorithms for parameter identification of photovoltaic cell/module," Journal of Renewable and Sustainable Energy, vol. 5, no. 5, Sep. 2013, Art. no. 053122, doi: 10.1063/1.4822054

[28] Z. Chen, L. Wu, P. Lin, Y. Wu, and S. Cheng, "Parameters identification of photovoltaic models using hybrid adaptive NelderMead simplex algorithm based on eagle strategy," Applied Energy, vol. 182, pp. 47-57, Nov. 2016, doi: 10.1016/j.apenergy.2016.08.083.

[29] X. Yuan, Y. Xiang, and Y. He, "Parameter extraction of solar cell models using mutative-scale parallel chaos optimization algorithm," Solar Energy, vol. 108, pp. 238-251, Oct. 2014, doi: 10.1016/j.solener.2014.07.013.

[30] J. Liang et al., "Classified perturbation mutation based particle swarm optimization algorithm for parameters extraction of photovoltaic models," Energy Conversion and Management, vol. 203, Jan. 2020, Art. no. 112138, doi:

Identification study of solar cell/module using recent optimization techniques (Mahmoud Abbas El-Dabah) 
10.1016/j.enconman.2019.112138.

[31] D. Yousri, D. Allam, M. B. Eteiba, and P. N. Suganthan, "Static and dynamic photovoltaic models' parameters identification using chaotic heterogeneous comprehensive learning particle swarm optimizer variants," Energy Conversion and Management, vol. 182, pp. 546-563, Feb. 2019, doi: 10.1016/j.enconman.2018.12.022.

[32] X. Gao et al., "Parameter extraction of solar cell models using improved shuffled complex evolution algorithm," Energy Conversion and Management, vol. 157, pp. 460-479, Feb. 2018, doi: 10.1016/j.enconman.2017.12.033.

[33] A. M. Shaheen, A. R. Ginidi, R. A. El-Sehiemy, and S. S. M. Ghoneim, "A forensic-based investigation algorithm for parameter extraction of solar cell models," IEEE Access, vol. 9, pp. 1-20, 2021, doi: 10.1109/ACCESS.2020.3046536.

[34] M. Said et al., "Estimating parameters of photovoltaic models using accurate turbulent flow of water optimizer," Processes, vol. 9, no. 4, Apr. 2021, Art. no. 627, doi: 10.3390/pr9040627.

[35] M. A. Elhosseini, R. A. El Sehiemy, Y. I. Rashwan, and X. Z. Gao, "On the performance improvement of elephant herding optimization algorithm," Knowledge-Based Systems, vol. 166, pp. 58-70, Feb. 2019, doi: 10.1016/j.knosys.2018.12.012.

[36] A. S. Bayoumi, R. A. El-Sehiemy, K. Mahmoud, M. Lehtonen, and M. M. F. Darwish, "Assessment of an improved three-diode against modified two-diode patterns of MCS solar cells associated with soft parameter estimation paradigms," Applied Sciences, vol. 11, no. 3, Jan. 2021, Art. no. 1055, doi: 10.3390/app11031055.

[37] R. Chenouard and R. A. El-Sehiemy, "An interval branch and bound global optimization algorithm for parameter estimation of three photovoltaic models," Energy Conversion and Management, vol. 205, Feb. 2020, Art. no. 112400, doi: 10.1016/j.enconman.2019.112400.

[38] P. J. Gnetchejo, S. Ndjakomo Essiane, P. Ele, R. Wamkeue, D. M. Wapet, and S. P. Ngoffe, "Important notes on parameter estimation of solar photovoltaic cell," Energy Conversion and Management, vol. 197, Oct. 2019, Art. no. 111870, doi: 10.1016/j.enconman.2019.111870.

[39] I. Ahmadianfar, A. A. Heidari, A. H. Gandomi, X. Chu, and H. Chen, "RUN beyond the metaphor: An efficient optimization algorithm based on Runge Kutta method," Expert Systems with Applications, vol. 181, Nov. 2021, Art. no. 115079, doi: 10.1016/j.eswa.2021.115079.

[40] T. Easwarakhanthan, J. Bottin, I. Bouhouch, and C. Boutrit, "Nonlinear minimization algorithm for determining the solar cell parameters with microcomputers," International Journal of Solar Energy, vol. 4, no. 1, pp. 1-12, Jan. 1986, doi: $10.1080 / 01425918608909835$.

[41] K. Nishioka, N. Sakitani, Y. Uraoka, and T. Fuyuki, "Analysis of multicrystalline silicon solar cells by modified 3-diode equivalent circuit model taking leakage current through periphery into consideration," Solar Energy Materials and Solar Cells, vol. 91, no. 13, pp. 1222-1227, Aug. 2007, doi: 10.1016/j.solmat.2007.04.009. 